\title{
Optimising Computer Laboratory Layout Based on Multiple Performance Measures
}

\author{
Hairulliza Mohamad Judi and Hazura Mohamed
}

\begin{abstract}
Awareness to select computer laboratory layout has been increased in recent years as more academic administration have come to realize its potential for contributing to conducive teaching and learning environment. Studies on physical design of computer laboratory including optimizing its layout to achieve comfort and fulfill its function are yet little. This paper proposes the optimization of computer laboratory layout using multiple performance measures. The use of grey relational analysis is presented to evaluate and select the best among the proposed four new layouts. The evaluation and selection were performed based on three performance parameters: capacity, total surface area and utility of space. The performance measures were considered to be of equal weight. The use of grey relational analysis shows reliable solution could be suggested that provide a better distinction among the given alternatives.
\end{abstract}

Index Terms-Modeling, learning environment, grey relational analysis.

\section{INTRODUCTION}

Academic organizations are facing challenges in using their facilities to support main activities: teaching, learning and research. This issue is related to layout management i.e. the arrangement of tools, and usage of space to achieve comfort and fulfill the purpose [1]. Layout plays an important role in developing a conducive environment that supports learning. Among important facilities that require good layout planning is computer laboratory. Computer labs must be designed intelligently and serve the purpose they were intended to serve [2], [3]. Generally, there are two types of users in academic computer laboratory: students and instructors [4]. The needs and requirements of these users need to be identified to ensure this facility supports the purpose especially in current development of learning environment.

The recent development of computer technology and availability has led to the rise of laptop and other computer ownership among students and eventually eliminated the need for campus computing laboratories [5], [6]. However, the continued need of computer laboratories in teaching and learning process is reasonable due to the need for standardized software and hardware configurations, high cost and complexity of many specialized software applications and limited number of software license to support educational

Manuscript received December 23, 2014; revised April 10, 2015. The publication of this paper was supported in part by Malaysian Education Ministry under Grant DPP-2014-019.

The authors are with the Software Technology and Management Research Centre (SOFTAM), Faculty of Information Sciences and Technology, Universiti Kebangsaan Malaysia, 43600 Bangi Malaysia (e-mail: hmj@ukm.edu.my, hazura.mohamed@ukm.edu.my). activities [7]

Awareness to select computer laboratory layout has been increased in recent years as more academic administration have come to realize its potential for contributing to conducive teaching and learning environment. Selecting the best arrangement may become crucial issue considering the number of students to occupy the room and hence the number of computers to cater the needs. For example, the frequency of student-to-student and student-to-teacher interactions indicated that the pod arrangement supported more collaboration than the straight row of laboratory arrangement [8].

Usually, as many as 40 students register for a certain programme in information technology and computer science courses, thus these numbers should be used to measure the capacity of the facility on a basis of one-computer-one student environment. A good computer laboratory layout could be determined by its ability to accommodate the required quantity, and provide enough space for movement and interaction between students and instructors

It is important to conduct evaluation for all possible layouts either when a computer laboratory is newly designed or is under renovation. The evaluation process is based on the requirement of users. For example, the evaluation methods are based on number of computers it could occupy and utility of space as measurement parameters. Quantitative measurement may give efficient evaluation as they give more objective and more accurate data processing. Therefore, three quantitative measurements are used in the study: capacity, total surface area and utility of space. The second and third measurement could be used independently as they measure different aspect each.

The evaluation process of computer laboratory layout is an example of various characteristics as evaluation factors together with multiple attributes decision problems. Selection of optimal layout in industrial setting requires for systematic procedure that takes into account the optimization of evaluation factors [9], [10]. The application of grey relational analysis is suitable for multiple attributes decision problems, especially for those problems with very unique characteristic [11].

This paper proposes the optimization of computer laboratory layout using multiple performance measures. The use of grey relational analysis is presented to evaluate and select the best among the proposed four new layouts as a case of computer facility management in Faculty of Information Science and Technology, Universiti Kebangsaan Malaysia. Four new layouts were proposed as part of results produced in industrial modeling and analysis project conducted by students undertaking TTTR3223 Industrial Simulation and 
Industry offered by the faculty [4]. The GRA model is apparently suitable to establish a complete and accurate evaluation for selecting computer laboratory layout.

\section{GREY RELATIONAL ANALYSIS}

Grey Relational Analysis (GRA) is a technique of Grey Systems Theory (GST). The term "grey" is used to represent a situation between two extremes: black and white [12]. While black is defined as situations with no information and white as those with perfect information, grey refers to a system in which part of information is known and part of information is unknown. Grey analysis presents a clear set of statements about system solutions. At one extreme, no solution can be defined for a system with no information. At the other extreme, a system with perfect information has a unique solution. In the middle, grey systems will give a variety of available solutions. The analysis does not attempt to find the best solution, but does provide techniques for determining a good solution, an appropriate solution for real world problems.

GRA is an impact evaluation model that measures the degree of similarity or difference between two situations based on the grade of relation [13]. GRA contains four steps to generate the global comparison among the alternatives [14]. It starts with the preparation of factor compatibility by considering three criterions i.e. capacity, total surface area and utility of space. Next, derivation of reference sequences is conducted for every layout design processing all performance values into a comparability sequence, in a process analogous to normalization. The calculation of grey relational coefficient is then produced to determine the closeness to optimum performance. After the entire grey relational coefficient has been calculated, the grey relational grade will be determined to evaluate and select the optimum solution for the new computer lab layout.

\section{METHOD}

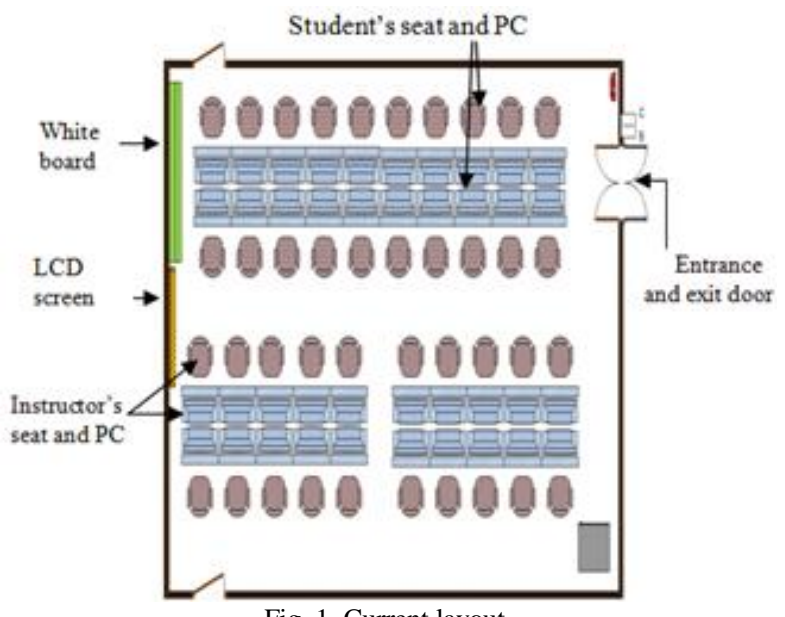

Fig. 1. Current layout.

In this study, the current layout of Industrial Application Computer Laboratory, in Faculty of Information Science and Technology, Universiti Kebangsaan Malaysia is evaluated. This laboratory is extensively used by TTTR3223 students. The research proposes new layout designs for the facility and identify the best layout that suits the purpose of the laboratory. Fig. 1 presents the current layout of the laboratory. It provides the arrangement of students' and instructor's seats and personal computer (PC), entrance and exit door, white board and Liquid Crystal Display (LCD) screen in the laboratory.

Fig. 2 to Fig. 5 present the new layout for this laboratory using various changes in the arrangement. Four designs are proposed to improve the current layout. The layouts are evaluated according to the requirement of users. The results of evaluation are presented in Table I. The statistics for the layout were compared using GRA. The results and discussions are presented in the next section.

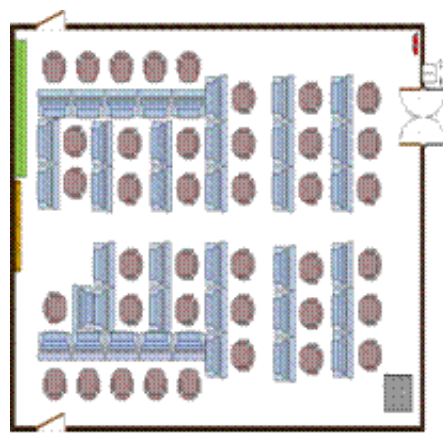

Fig. 2. New layout 1.

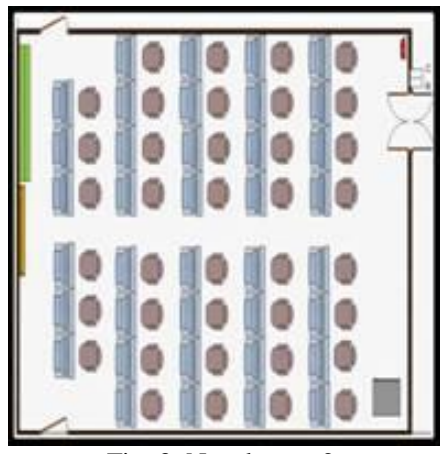

Fig. 3. New layout 2 .

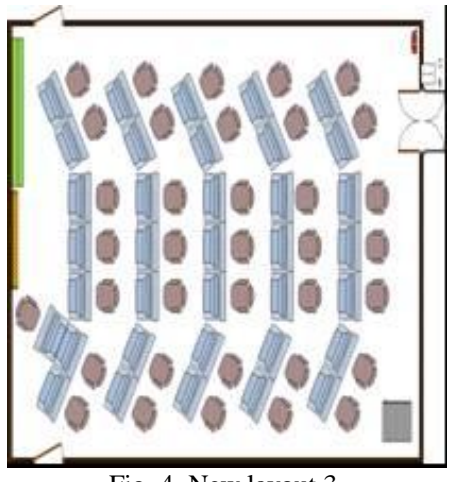

Fig. 4. New layout 3

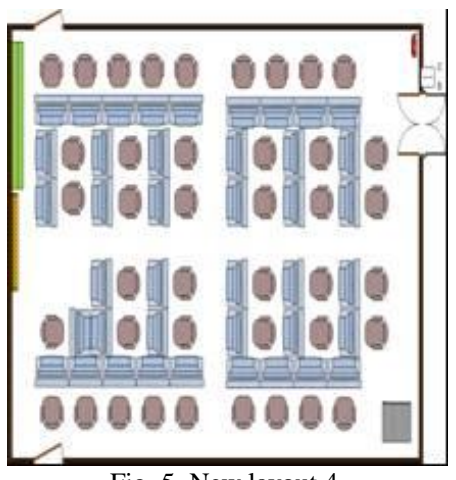

Fig. 5. New layout 4 
TABLE I: COMPARISON OF LAYOUT

\begin{tabular}{llll}
\hline \hline Layout & Capacity & Total surface area & Utility of space \\
\hline Layout 1 & 39 & $621 \mathrm{ft}^{2}$ & $64.6 \%$ \\
Layout 2 & 38 & $678 \mathrm{ft}^{2}$ & $70.6 \%$ \\
Layout 3 & 36 & $738 \mathrm{ft}^{2}$ & $76.8 \%$ \\
Layout 4 & 41 & $633 \mathrm{ft}^{2}$ & $65.9 \%$ \\
Current layout & 40 & $618 \mathrm{ft}^{2}$ & $64.3 \%$ \\
\hline \hline
\end{tabular}

\section{ANALYSIS}

In the present study, the capacity, total surface area and utility of space and the entire performance measures for the five layout alternatives are shown in Table I. Typically, higher values of the capacity and lower values of total surface area and utility of space as the target values are desirable. Thus, the normalized data sequences of the capacity has larger-the-better characteristic and total surface area and utility space have smaller-the-better characteristics.

The normalized value of the capacity, total surface area and utility of space are set to be the reference sequence. The result of grey relational generating for capacity of Layout 1 is equal to 0.6. Table II lists all of the results of grey relational generating, $X_{0}$ is reference sequence. The grey relational coefficients were calculated to indicate the performance of each alternative. The entire results for the grey relational coefficient are shown in Table III. In this case, all performance measures have an equal importance. Thus, the weights of the three performance measures were all the same $(1 / 3)$.

The grey relational grade is presented in Table IV, together with the ranking results of GRA. This shows that the rank of Current Layout is the 3rd. Layout 1 appears to be in the first rank and the best among the alternatives. This layout should be suggested as the future layout design for a new laboratory, after considering the three measurements of capacity, total surface area and utility of space. The example here shows that systematic evaluation of multiple performance measures problem using GRA can reduce the risk of a poor design.

TABLE II: GREY RELATIONAL SEQUENCE

\begin{tabular}{llll}
\hline \hline Layout & Capacity & Total surface area & Utility of space \\
\hline $\mathrm{X}_{0}$ & 1.000 & 1.000 & 1.000 \\
Layout 1 & 0.600 & 1.000 & 0.976 \\
Layout 2 & 0.400 & 0.089 & 0.496 \\
Layout 3 & 0.000 & 0.000 & 0.000 \\
Layout 4 & 0.800 & 0.178 & 1.000 \\
Current layout & 1.000 & 0.155 & 0.872 \\
\hline \hline
\end{tabular}

TABLE III: GREY RELATIONAL COEFFICIENT

\begin{tabular}{llll}
\multicolumn{4}{c}{ TABLE III: GREY RELATIONAL COEFFICIENT } \\
\hline \hline Layout & Capacity & Total surface area & Utility of space \\
\hline Layout 1 & 0.556 & 1.000 & 0.954 \\
Layout 2 & 0.455 & 0.354 & 0.498 \\
Layout 3 & 0.333 & 0.333 & 0.333 \\
Layout 4 & 1.000 & 0.327 & 0.796 \\
Current layout & 0.714 & 0.378 & 1.000 \\
\hline \hline
\end{tabular}

TABLE IV: GREY RELATIONAL GRADE AND RANK

\begin{tabular}{lll}
\hline \hline Layout & Grade & Rank \\
\hline Layout 1 & 0.837 & 1 \\
Layout 2 & 0.436 & 4 \\
Layout 3 & 0.333 & 5 \\
Layout 4 & 0.723 & 2 \\
Current layout & 0.697 & 3 \\
\hline \hline
\end{tabular}

\section{DISCUSSION AND CONCLUSIONS}

Selecting the best alternative design is very important in developing new computer laboratory layout and work environments especially when multiple performance measures are considered simultaneously. The use of grey relational analysis to identify optimum selection of laboratory layout can generate reliable solutions efficiently since it provides a better distinction among the alternatives, especially the order of alternatives [9], [10]. This feature makes GRA possesses the merit of point set topology and as such, the global comparison between two sets of data is undertaken instead of local comparison by measuring the distance between two points [15]. Thus, it avoids the side effect of subjective setting of parameters within the model.

The results presented using GRA suggest Layout 1 appears to be in the first rank and the best among the alternatives. The selection is considered using three measurements of capacity, total surface area and utility of space. Layout 1 presents a physical space that emphasis U-pod design as opposed to straight rows. This finding is consistent with Callahan that shows pod-arranged computer lab classroom had better function in terms of Computer, Workspace, and Visual environments than straight rows [8]. The availability of physical space that support interactions between students and instructors and among students offer a viable environment in supporting students to learn collaboratively and be more creative [1].

In this study, all performance measures were considered to be of equal weight. However, for future research the weighting method may be proposed. Furthermore, both quantitative and qualitative measurements can be applied to consider a more comprehensive evaluation of layout performance [11]. Future research may examine the contribution of physical design of computer laboratory on education achievement since little has been written in the topic [16].

\section{REFERENCES}

[1] R. Daniel and K. Fleischmann, "Designing a learning space for creativity and collaboration: From studio to computer lab in design education," Learning Space Design in Higher Education, Learning in Higher Education Series, Libri Publishing, Oxford, UK, pp. 191-208. 2014.

[2] J. Garger. The four best computer laboratory layouts for schools. (2010). [Online]. Available: http://www.brighthub.com/computing/hardware/articles/52714.aspx

[3] N. Salleh, A. F. M. Ayub, and N. Z. Abidin, "Persepsi pelajar terhadap persekitaran fizikal makmal komputer: Perbandingan Antara Dua Makmal Komputer yang Berbeza Susun Atur," Journal of Techno-Social, pp. 59-74, 2010.

[4] M. J. Hairulliza, Y. Z. Cheng, T. B. Seong, L. Z. Yuan, H. H. Yen, and L. W. Voon, "A case of computer laboratory layout modelling and analysis," in Proc. 2011 International Conference on Electrical Engineering and Informatics, pp. H12-H14, Bandung, 2011.

[5] S. D. Burd, A. F. Seazzu, and C. Conway, "Virtual computing laboratories: A case study with comparisons to physical computing laboratories," Journal of Information Technology Education, vol. 8, pp. 54-78, 2009.

[6] M. O. M. El-Hussein and J. C. Cronje, "Defining mobile learning in the higher education landscape," Educational Technology \& Society, vol. 13, pp. 12-21, 2010.

[7] B. L. Hawkins and D. G. Oblinger, "The myth about the need for public computer labs: students have their own computers, so public labs are no longer needed," EDUCAUSE Review, vol. 42, pp. 10-11, 2007.

[8] J. L. Callahan, "Effects of different seating arrangements in higher education computer lab classrooms on student learning, teaching style, 
and classroom appraisal," Master Degree Dissertation, University of Florida, 2004.

[9] B. Djebedjian, A. Yaseen, and R. Ezzeldin, "Reliability-based optimization of layout and sizing of water distribution systems," in Proc. Twelfth International Water Technology Conference, pp. 759-779, Alexandria, Egypt, 2008

[10] M. H. Afshar, "Evaluation of selection algorithms for simultaneous layout and pipe size optimization of water distribution networks," Scientia Iranica, vol. 14, pp. 23 -32, 2007.

[11] P. Wang, P. Meng, J. Zhai, and Z. Zhu, "A hybrid method using experiment design and grey relational analysis for multiple criteria decision making problems," Knowledge-Based Systems, vol. 53, pp. 100-107, 2013.

[12] N. Geeta, U. Moin, and K. Arvinder, "A hybrid technique using grey relational analysis and regression for software effort estimation using feature selection," International Journal of Soft Computing and Engineering (IJSCE), vol. 1, pp. 20-27, 2012.

[13] H. W. Shi and Y. Deng, "A grey model for evaluation of information systems security," Journal of Computers, vol. 7, no. 1, 2012.

[14] T. Yang, Y. Kuo, P. David, and K. H. Chen, "A multiple attribute group decision making approach for solving problems with the assessment of preference relations," Mathematical Problems in Engineering, 2014.

[15] W. K. Chan and T. K. L. Tong, "Multiple criteria decision making with life cycle assessment for material selection of composites," EXPRESS Polymer Letters, vol. 5, no. 12, pp. 1062-1074, 2011.

[16] R. Hickey, "Beyond class hours: The GIS lab as a center of geographic education," International Journal of Applied Geospatial Research vol. 1 , pp. 46-61, 2010

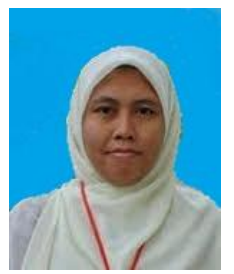

Hairulliza Mohamad Judi received her B.Sc. degree in actuarial science from Universiti Kebangsaan Malaysia, in 1995 and the M.S. degree in quality and productivity improvement from the same university in 1996. Since 1997, she has been an academic member with the Department of Industrial Computing, Faculty of Information Sciences and Technology, Universiti

Kebangsaan Malaysia. Her research interests include quality measurement and analysis of manufacturing and service process, usability of software products with particular interest in sustainable product development and mobile education application.

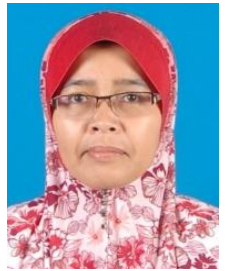

Hazura Mohamed received her B.Sc. degree in mathematics and the M.Sc. degree in quality and productivity improvement from Universiti Kebangsaan Malaysia. She obtained her PhD in mathematics from Universiti Teknologi Malaysia.

Since 2001, she has been an academic member with the Department of Industrial Computing, Faculty of Information Sciences and Technology, Universiti Kebangsaan Malaysia. Her research interests include service performance evaluation, quality measurement and analysis of manufacturing and service process. 